\title{
Interferences of silica nanoparticles in green fluorescent protein folding processes
}

Géraldine Klein(1,2), Stéphanie Devineau (1), Jean Christophe Aude (2), Yves Boulard (3), Hélène Pasquier (4), Jean Labarre (2), Serge Pin (1), Jean Philippe Renault (1)

(1) NIMBE, CEA/DSM/IRAMIS et UMR3685 CNRS, CEA-Saclay, Gif sur Yvette France

(2) Service de Biologie Intégrative et Génétique Moléculaire, iBiTec-S, FRE3377 CEA-CNRS-Université ParisSud, CEA-Saclay, Gif sur Yvette France

(3) Service de Bioénergétique, Biologie Structurale et Mécanismes, iBiTec-S, UMR 9198 CEA-CNRS-Université Paris-Sud, CEA-Saclay, Gif sur Yvette France

(4) Laboratoire de Chimie Physique, UMR 8000, CNRS-Université Paris-Sud, Orsay, France

\section{Supporting information}
A) Proteomic data
B) Spontaneous and catalyzed refolding kinetics
C) Distribution of $K$ values in Langmuir-Freundlich isotherms
D) Competition kinetics of dGFP between adsorption on NPs and refolding.
E) Additional refolding curves
F) Gel Electrophoresis of adsorbed $\mathrm{HSP}_{60+10}$
G) Additional Isotherms
H) Competition of NP for unfolded protein capture
I) GFP sequence and circular dichroism spectra of acid-denatured GFP
J) References 


\begin{tabular}{|c|c|c|c|c|}
\hline & Name & ORF & Ratio (a) & Function (b) \\
\hline \multirow{31}{*}{ 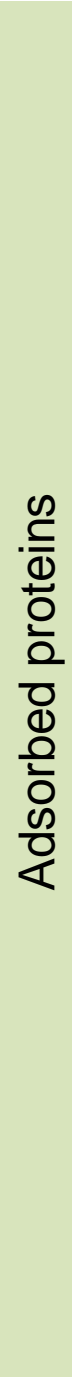 } & GRS1 & YBR121C & 11.11 & \\
\hline & EGD2 & YHR193C & 8.33 & 'de novo' cotranslational protein folding \\
\hline & ILV2 & YMR108W & 7.69 & \\
\hline & SSB1 & YDL229W & 5.00 & 'de novo' cotranslational protein folding \\
\hline & PAB1 & YER165W & 5.00 & \\
\hline & STI1 & YOR027W & 4.35 & protein folding \\
\hline & KAR2 & YJL034W & 4.00 & response to unfolded protein \\
\hline & RPS5 & YJR123W & 3.7 & \\
\hline & EFB1 & YAL003W & 3.57 & \\
\hline & RPSOA & YGR214W & 3.33 & \\
\hline & SAM2 & YDR502C & 3.23 & \\
\hline & FRS1 & YLR060W & 3.23 & \\
\hline & SSE1 & YPL106C & 3.13 & protein folding and refolding \\
\hline & SSC1 & YJR045C & 3.03 & protein unfolding and refolding \\
\hline & EGD1 & YPL037C & 3.03 & 'de novo' cotranslational protein folding \\
\hline & HYP2 & YEL034W & 2.94 & \\
\hline & SHP1 & YBL058W & 2.78 & \\
\hline & SAM1 & YLR180W & 2.63 & \\
\hline & ILV3 & YJR016C & 2.63 & \\
\hline & SOD2 & YHR008C & 2.5 & \\
\hline & VMA1 & YDL185W & 2.33 & \\
\hline & HSP60 & YLR259C & 2.33 & $\begin{array}{c}\text { protein refolding } \\
\text { protein stabilization } \\
\text { 'de novo' cotranslational protein folding }\end{array}$ \\
\hline & YPL088W & YPL088W & 2.17 & \\
\hline & SSA1 & YAL005C & 2.17 & protein folding \\
\hline & LYS9 & YNR050C & 2.17 & \\
\hline & DAL1 & YIR027C & 2.00 & \\
\hline & TIF3 & YPR163C & 1.89 & \\
\hline & KRS1 & YDR037W & 1.72 & \\
\hline & HCR1 & YLR192C & 1.67 & \\
\hline & PUB1 & YNL016W & 1.64 & \\
\hline & VMA2 & YBR127C & 1.59 & \\
\hline
\end{tabular}

Table S1 : From Mathé et al. ${ }^{1}$ functions related to the cellular protein machinery among the 30 most affine proteins for silica Np.(a) ratio (presence in the absorbed fraction)/(presence in the non absorbed fraction) (b) biological function given by the Saccharomyces Genome Database

\section{B) Spontaneous and catalyzed refolding kinetics}

Data were fitted using the pseudo first order equation

$$
\mathrm{R}(\mathrm{t})=\mathrm{R}_{\infty}(1-\exp (-\mathrm{kt}))+\mathrm{R}_{0} \quad(\text { eq } \mathrm{S} 1)
$$

Where $\mathrm{k}$ is the folding kinetic constant and $\mathrm{R}$ the refolding percentage. 


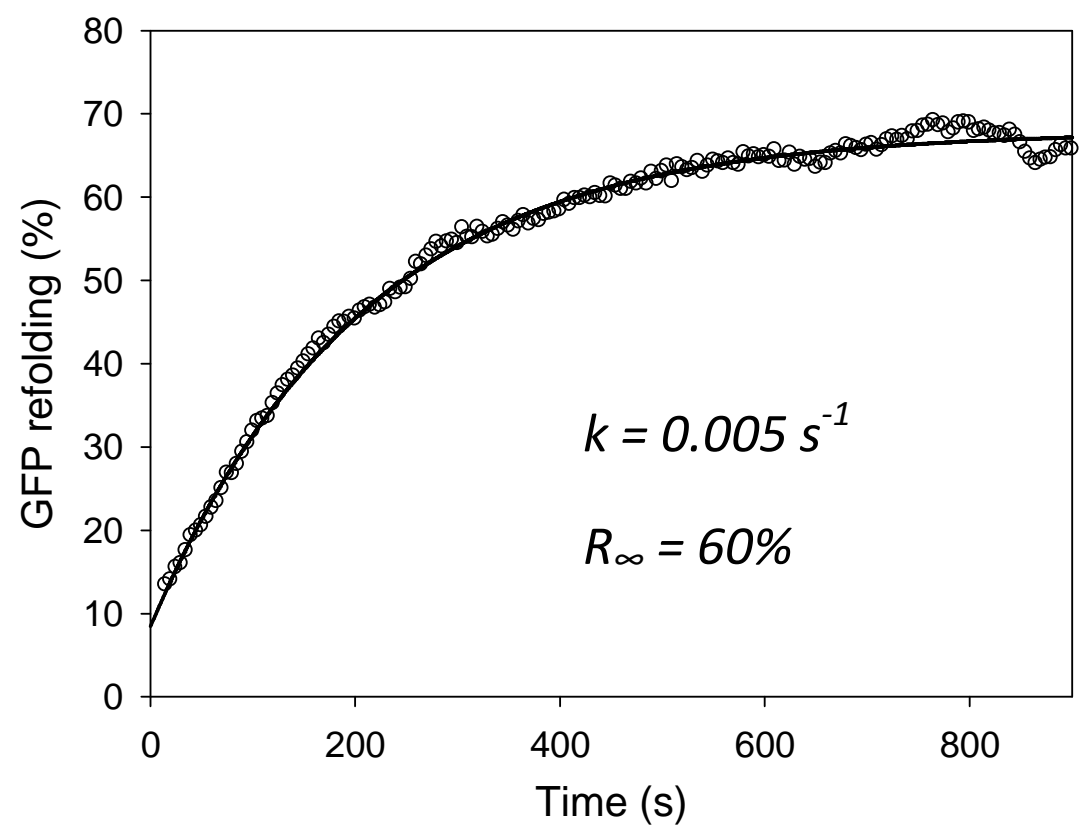

Figure S1. Acid-denatured GFP spontaneous refolding kinetics. The adjustment using equation $\mathrm{S} 1$ is shown as a black line.

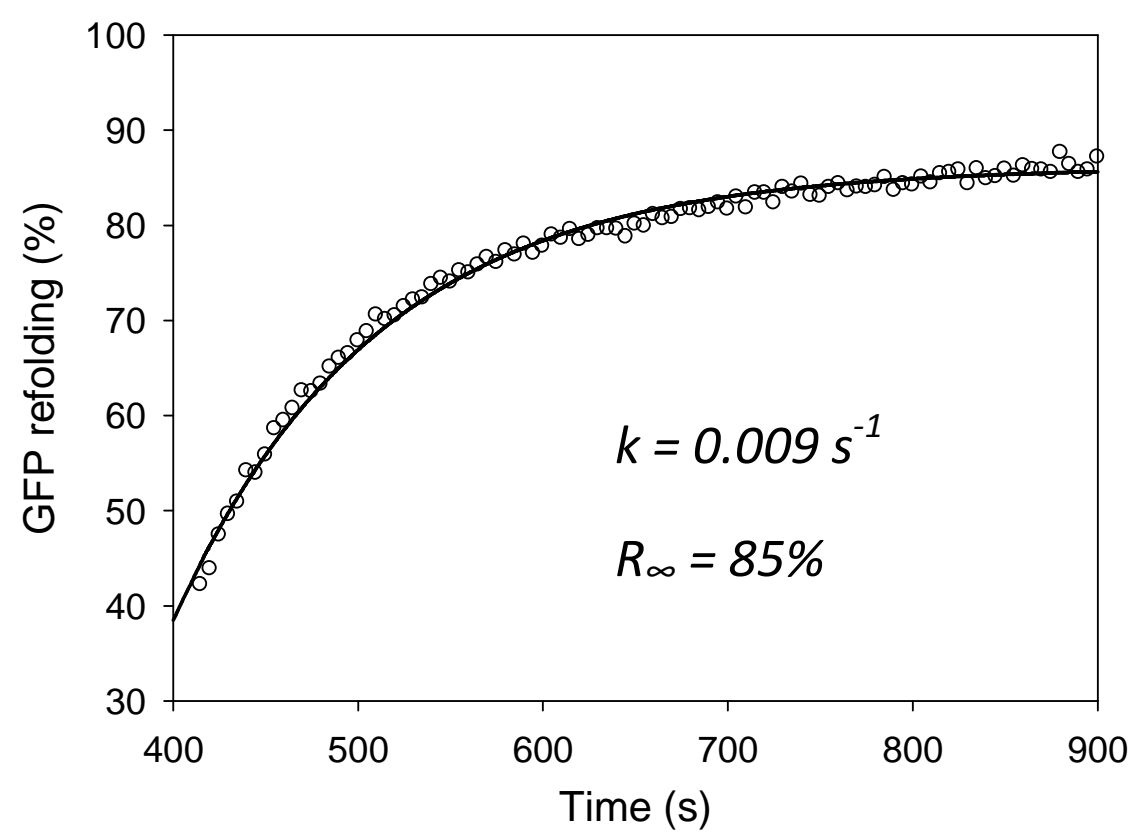

Figure S2. $\mathrm{HSP}_{60+10}$ catalyzed acid-denatured GFP refolding kinetics. The adjustment using equation $\mathrm{S} 1$ is shown as a black line. 
C) Distribution of $K$ values in Langmuir-Freundlich isotherms ${ }^{2}$

$$
p(K)=2.3 n K_{a d s}^{n} K^{-n} \times \frac{\left(1+2 K_{a d s}^{n} K^{-n}+K_{a d s}^{2 n} K^{-2 n}+4 K_{a d s}^{n} K^{-n} m^{2}-K_{a d s}^{2 n} K^{-2 n} n^{2}-n^{2}\right)}{\left(1+K_{a d s}^{n} K^{-n}\right)^{4}}
$$

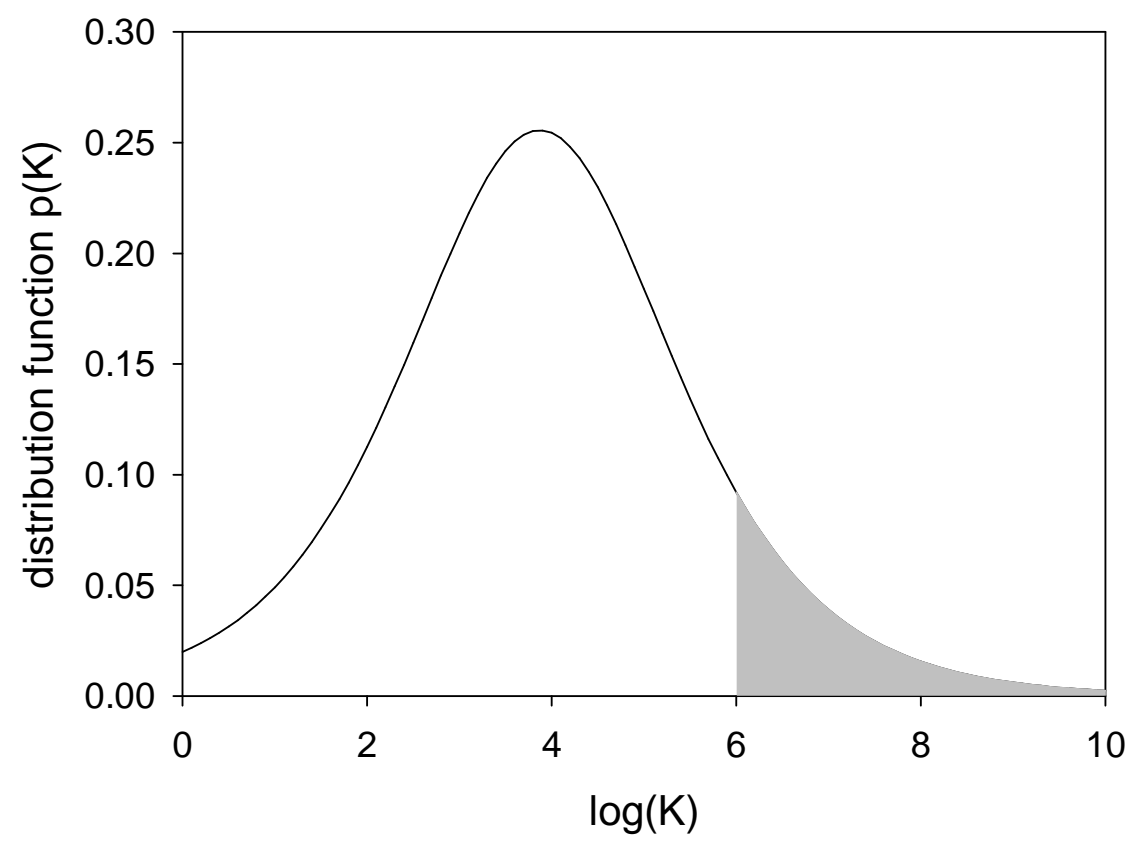

Figure S3 : Distribution function of the idGFP/NP adsorption affinity constants. The grey area represents $10 \%$ of the total area under the curve.

\section{D) Competition kinetics of dGFP between adsorption on NPs and refolding.}

Using a standard kinetic formalism, ${ }^{3}$ we can write

$$
\frac{F_{0}}{F}=1+\frac{k_{2}\left(S_{N P}\right)}{k_{1}}
$$

Where $\mathrm{F}$ is the fluorescence level that is achieved upon spontaneous refolding, $\mathrm{S}_{\mathrm{NP}}$ is the concentration in adsorption sites, and $\mathrm{k}_{1}$ is the spontaneous refolding kinetic constant $\left(0.005 \mathrm{~s}^{-1}\right)$.

The data of figure 3 are converted in figure S4. 


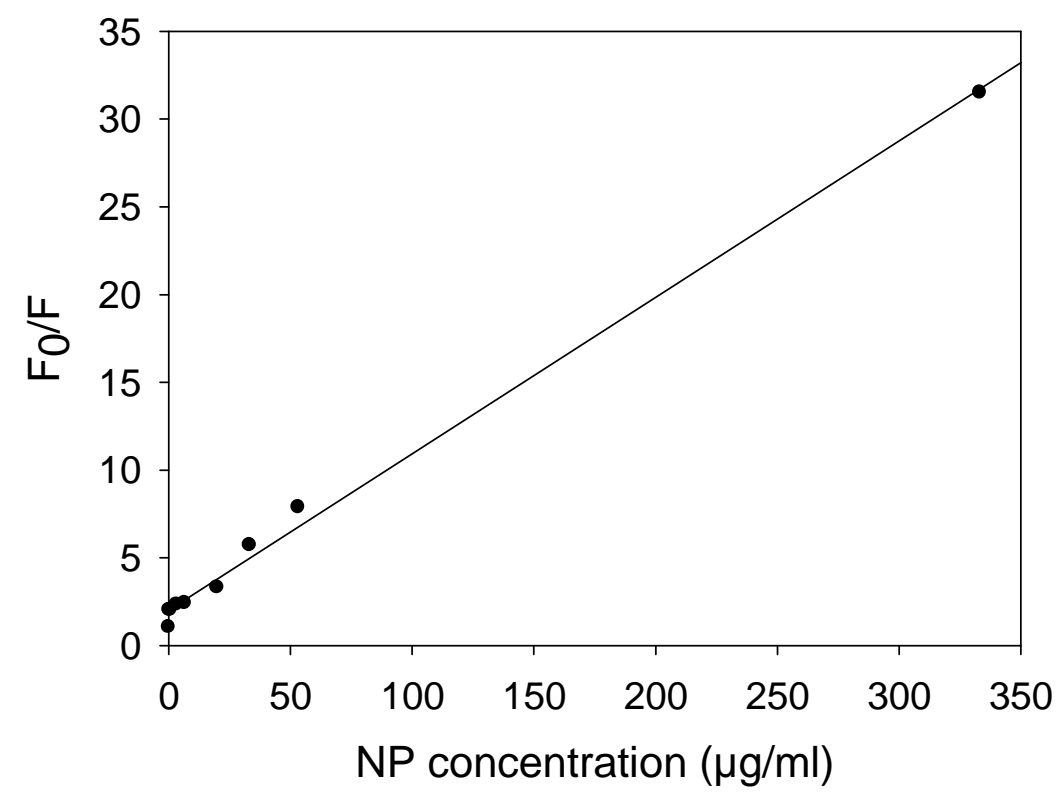

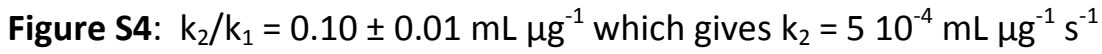

To convert $k_{2}$ in $\mathrm{M}^{-1} \mathrm{~s}^{-1}$, the main uncertainty lies in the number of sites per silica surface unit. For the silica nanoparticles considered here (specific surface area of $170 \mathrm{~m}^{2} \mathrm{~g}^{-1}$ and a maximum adsorbed GFP amount of $\left.3 \mathrm{mg} \mathrm{m} \mathrm{m}^{-2}\right), 1 \mu \mathrm{g} / \mathrm{mL}$ in NPs can adsorb $0.5 \mu \mathrm{g} / \mathrm{mL}$ in protein, which gives a concentration of protein adsorption sites of $14.4 \mathrm{nM}$. These assumptions give $k_{2}=35000 \mathrm{M}^{-1} \mathrm{~s}^{-1}$

\section{E) Additional refolding curves}

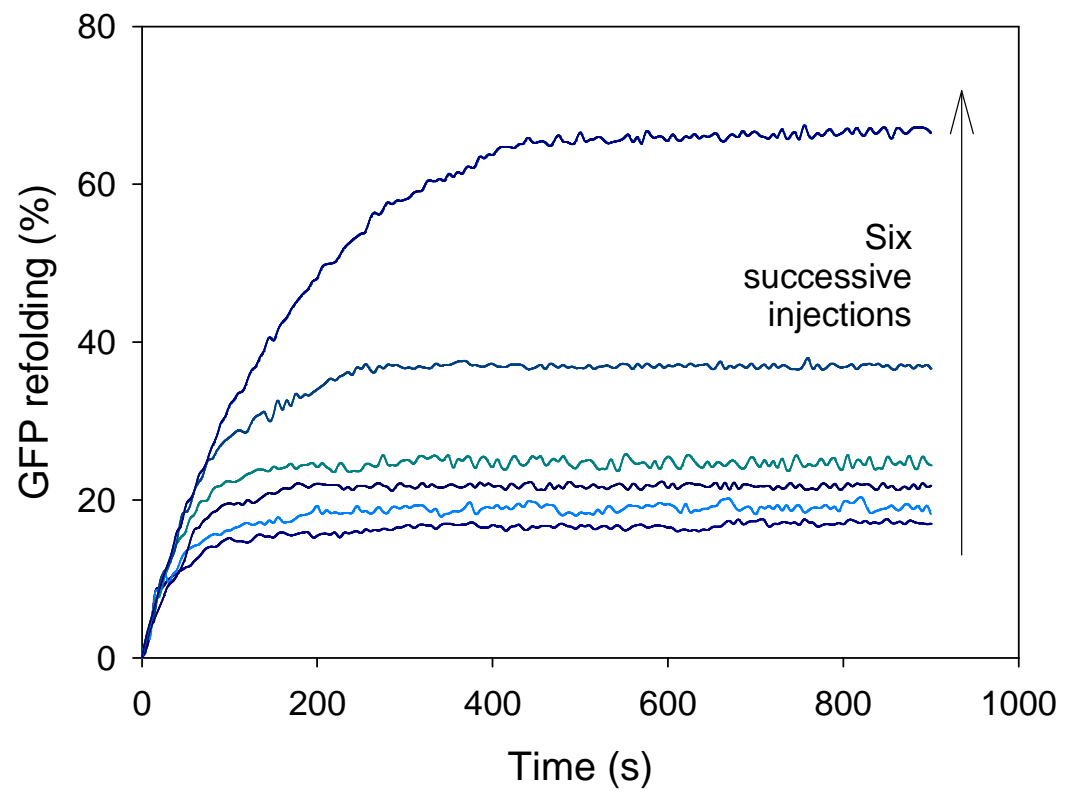

Figure S5: Spontaneous refolding of acid-denatured GFP in the presence of BSA coated $\mathrm{SiO}_{2}$ nanoparticles ( $40 \mu \mathrm{g} \cdot \mathrm{mL}^{-1}$ in $\mathrm{SiO}_{2}, 5 \mu \mathrm{g} \cdot \mathrm{mL}^{-1}$ in absorbed BSA). The curves represent 6 successive injections of $1 \mathrm{mg} . \mathrm{L}^{-1}$ of acid-denatured GFP to mimic the adsorption isotherm (Fig. 4) 


\section{F) Gel electrophoresis of adsorbed $\mathrm{HSP}_{60+10}$}

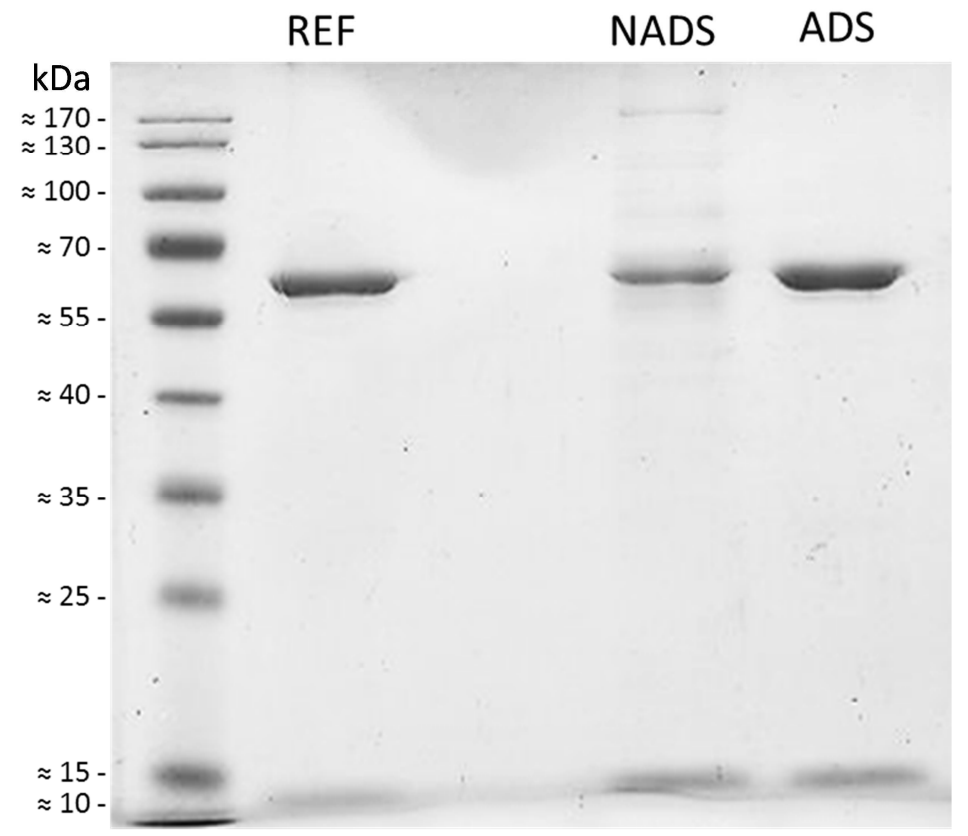

Figure S6 : SDS-PAGE gel electrophoresis of $\mathrm{HSP}_{60+10}$ complexes exposed to nanoparticles. Lines NADS : non adsorbed fraction; ADS adsorbed fraction ; REF initial mixture.

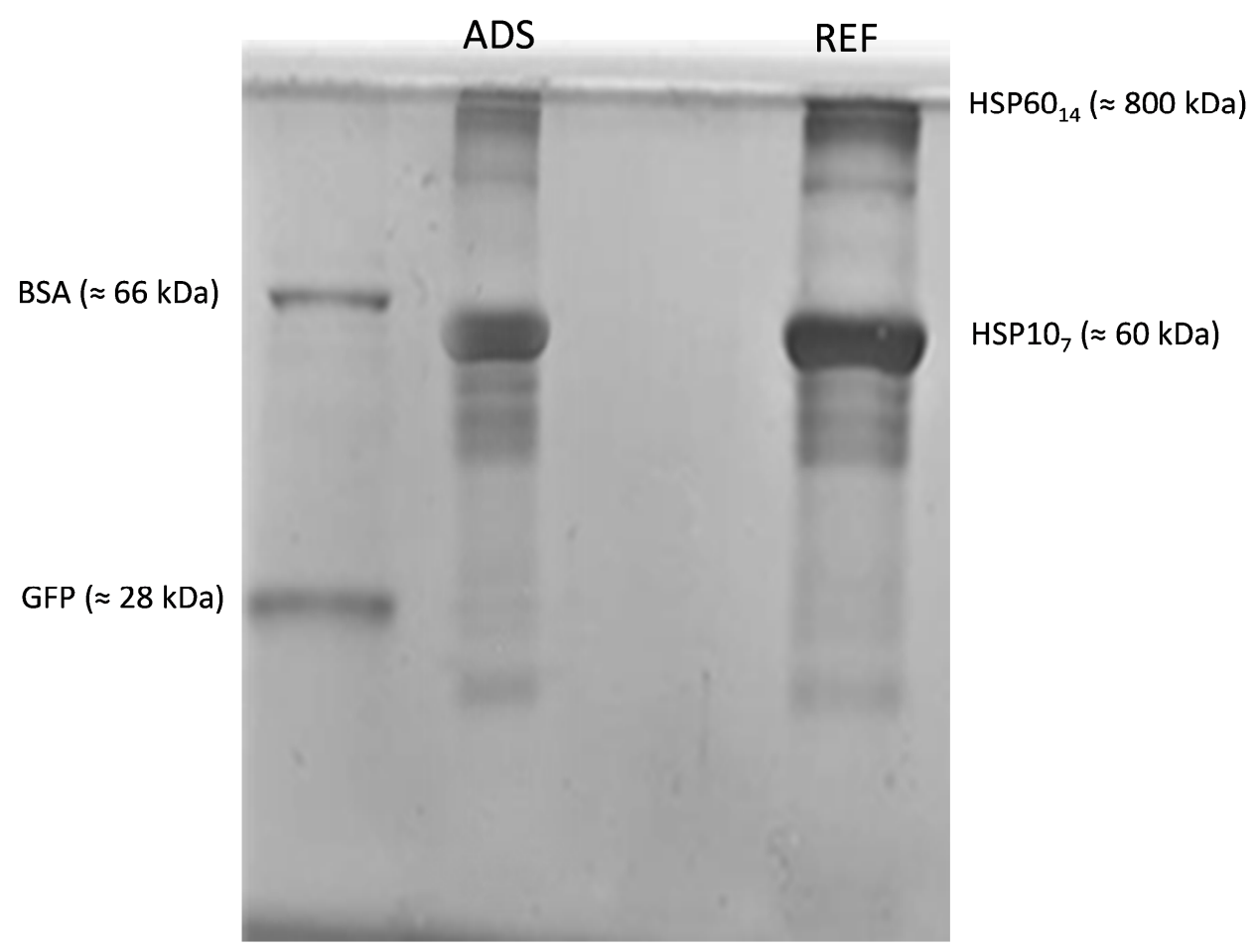

Figure S7 : N-PAGE gel electrophoresis of $\mathrm{HSP}_{60+10}$ mixtures exposed to nanoparticles. Lines ADS adsorbed fraction, REF: initial protein mixture 


\section{Gel preparation}

The non-denaturing native- and sodium dodecylsulfate-polyacrylamide gel electrophoresis (N-PAGE and SDS-PAGE respectively) were performed with a vertical slab mini gel unit (Hoefer Inc., MA, USA) using $1 \mathrm{~mm}$ thick gels as described by Laemmli (1970). The protein samples were prepared in 0.05 Tris- $\mathrm{HCl}$ buffer $(\mathrm{pH} 6.8)$ containing $10 \%(\mathrm{w} / \mathrm{v})$ glycerol and $0.05 \%(\mathrm{w} / \mathrm{v})$ bromophenol blue with or without 2-mercaptoethanol and SDS depending on PAGE used.

In case of SDS-PAGE, proteins were resolved on $12 \%$ acrylamide gel following denaturation by boiling for $5 \mathrm{~min}$ in SDS sample buffer, while in N-PAGE proteins were resolved on $6 \%$ acrylamide gel without boiling. The electrophoresis was carried out using Tris-glycine buffer $(0.025 \mathrm{mM}$ Tris and and $0.192 \mathrm{M}$ glycine, pH 8.5) with $20 \mu \mathrm{g}$ proteins loaded per lane.

The protein bands were fixed with solution containing acid acetic $(5 \%, v / v)$ for $5 \mathrm{~min}$, then stained for 30 min with $0.25 \%(w / v)$ Coomassie brilliant blue G-250, and destained by repeated washing using a solution containing $20 \%$ methanol and $10 \%(\mathrm{v} / \mathrm{v})$ acid acetic. PageRuler prestained protein ladder, (Thermo Scientific) was added for SDS-PAGE reference.

\section{G) Additional Isotherms}

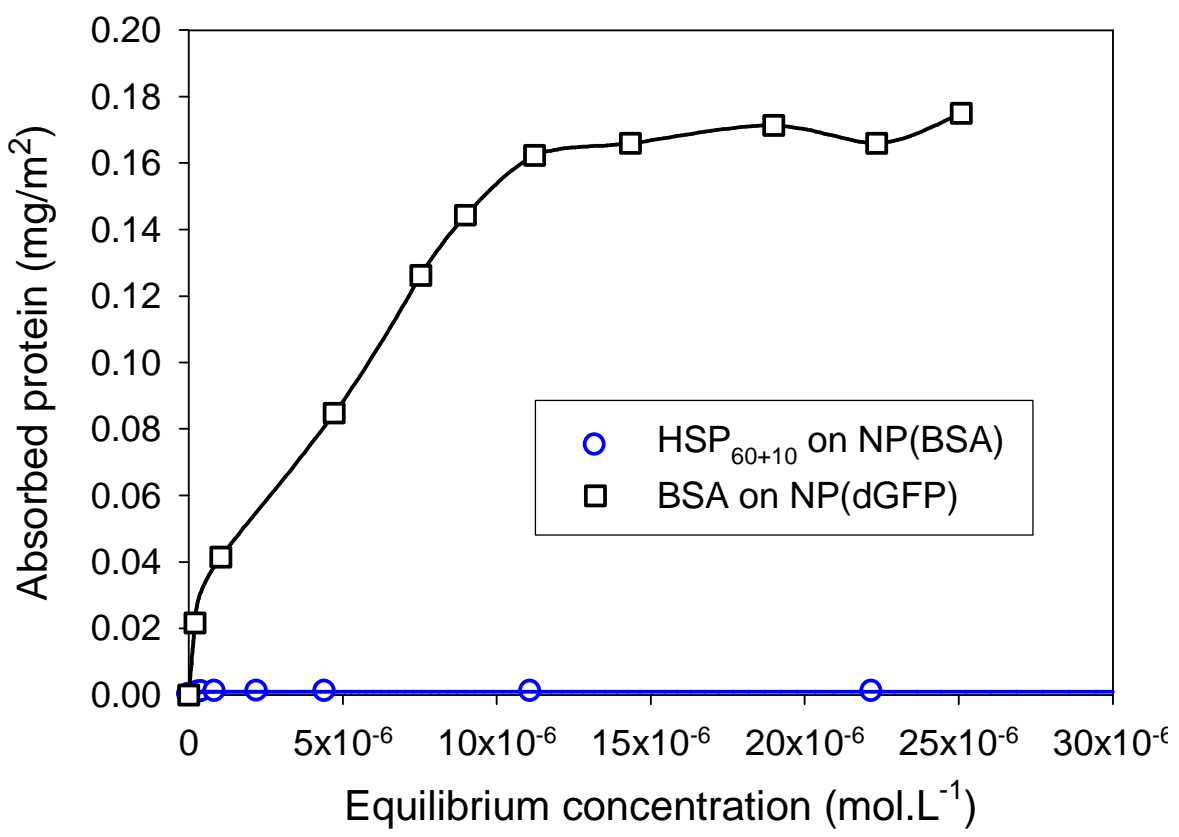

Figure S8. Adsorption isotherms for $\mathrm{HSP}_{60+10}$ on $\mathrm{BSA}$ saturated nanoparticles (blue circle) and of BSA on dGFP saturated nanoparticles (black square) 


\section{H) Competition of NP for unfolded protein capture}

The competition between NP and HSP for unfolded protein capture can be written as

$$
\mathrm{dProt}+\mathrm{S}_{\mathrm{NP}} \rightarrow \mathrm{dProt}_{\text {adsorbed }} \quad \mathrm{k}_{\mathrm{s} 4} \approx 3.510^{4} \mathrm{~L} \mathrm{~mol}^{-1} \mathrm{~s}^{-1}
$$

where $S_{N P}$ is an adsorption site on NP surface.

$$
\mathrm{dProt}+\mathrm{HSP} \rightarrow \mathrm{HSP}-\text { Prot } \quad \mathrm{k}_{\mathrm{s} 5} \quad \text { (eq S5) }
$$

The kinetic constant of unfolded protein capture by $\mathrm{HSP}_{60+10} \mathrm{k}_{55}$ are expected to depend on the protein but are usually in the $10^{4}-10^{6} \mathrm{M}^{-1} \mathrm{~s}^{-1}$ range. ${ }^{4} \mathrm{HSP}_{60+10}$ represents about one percent of the total protein content, i.e. a few $\mathrm{mg} / \mathrm{mL}^{.}$. This corresponds to a $1 \mu \mathrm{M}$ concentration and to an unfolded protein capture time constant in the $1 \mathrm{~s}^{-1} 0.01 \mathrm{~s}^{-1}$ range.

The kinetic constant of unfolded protein capture by NP was measured here as $\mathrm{k}_{\mathrm{s} 4}=3.510^{4} \mathrm{~mL} \mu \mathrm{g}^{-1} \mathrm{~s}^{-1}$ This corresponds for $10 \mathrm{\mu g} / \mathrm{mL}$ in NPs to a capture time constant of $3.510^{-3} \mathrm{~s}^{-1}$.

The unfolded protein will be captured by HSP or by NP in proportion to the time constants of the reaction S4 and S5. Here $66 \%$ on HSP vs $33 \%$ on NP if the capture by HSP is in the low range $\left(10^{4} \mathrm{M}^{-1}\right.$ $\left.\mathrm{s}^{-1}\right)$ and $99.5 \%$ on HSP vs $0.5 \%$ on NP if the capture by HSP is in the high range. $\left(10^{6} \mathrm{M}^{-1} \mathrm{~s}^{-1}\right)$

If we consider now the competition between surface capture and spontaneous folding

$$
\begin{aligned}
\mathrm{dProt}+\mathrm{S}_{\mathrm{NP}} \rightarrow \mathrm{dProt}_{\text {adsorbed }} & \mathrm{k}_{\mathrm{s} 4} \approx 3.510^{4} \mathrm{~L} \mathrm{~mol}^{-1} \mathrm{~s}^{-1} \\
\mathrm{dProt} \rightarrow \text { Prot } & \mathrm{k}_{\mathrm{s} 6} \approx 0.1 \mathrm{~s}^{-1} \quad \text { (eq S6) }
\end{aligned}
$$

The unfolded protein will be captured by NP in proportion to the time constants of the reaction S4 and S6, i.e. with about $5 \%$ of efficiency. 


\section{I) GFP sequence and circular dichroism spectra of native and acid-denatured GFP}

The GFP used was a enhanced GFP of sequence :

MRGSHHHHHHGVSKGEELFTGVVPILVELDGDVNGHKFSVSGEGEGDATYGKLTLKFICTTGKLPVPWPTLVTTLT YGVQCFSRYPDHMKQHDFFKSAMPEGYVQERTIFFKDDGNYKTRAEVKFEGDTLVNRIELKGIDFKEDGNILGHKLE YNYNSHNVYIMADKQKNGIKVNFKIRHNIEDGSVQLADHYQQNTPIGDGPVLLPDNHYLSTQSALSKDPNEKRDH MVLLEFVTAAGITLGMDELYK

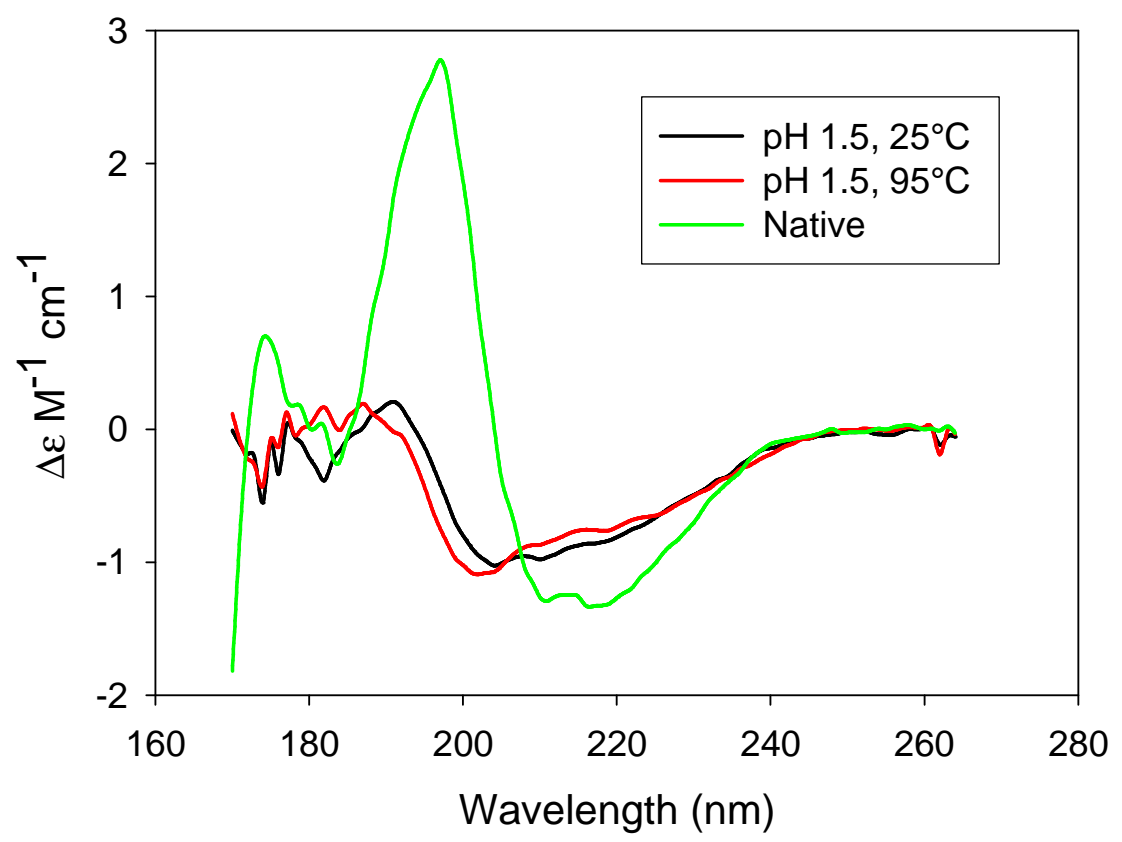

Figure S9. Synchroton radiation circular dichroïsm spectra of GFP at neutral and acid pHs. In green. SRCD spectrum of native GFP at $\mathrm{pH} 7.5$ and $25^{\circ} \mathrm{C}$. SRCD spectra of acid denaturated GFP at pH 1.5 (dGFP) were recorded at $25^{\circ} \mathrm{C}$ (black line) and then at $95^{\circ} \mathrm{C}$ (red line). The analogies between the spectra obtained at high and low temperature, $\mathrm{pH} 1.5$, show that the GFP is almost completely unfolded in our experimental conditions.

SRCD spectra were carried out on the DISCO beamline at Soleil synchrotron (Gif sur Yvette, France). Calcium Fluoride circular cuvettes (Hellma) ${ }^{6}$ of $15.5 \mu \mathrm{m}$ were used. Protein concentrations were 13 $\mathrm{mg} / \mathrm{L}$ at $\mathrm{pH} 1.5$ and $14 \mathrm{mg} / \mathrm{L}$ at pH 7.5. All samples were equilibrated against their buffer for 1 night (5 $\mathrm{mM}$ Tris- $\mathrm{HCl}, 62.5 \mathrm{mM} \mathrm{HCl}$ at $\mathrm{pH} 1.5$ and $10 \mathrm{mM}$ Tris- $\mathrm{HCl}$ at pH 7.5). SRCD spectra were achieved by averaging 3 scans, from 170 to $265 \mathrm{~nm}$ with $1 \mathrm{~nm}$ intervals per second. Three consecutive scans of the baseline (using the buffer) were recorded in the same procedure, averaged and then were subtracted from those of corresponding samples. The $260-265 \mathrm{~nm}$ region was set to zero, and the resulting spectra were calibrated with CSA (D-10-camphorsulfonic acid) using the CDtool software. ${ }^{7}$ 


\section{$\underline{J \text { References }}$}

1. Mathe, C.; Devineau, S.; Aude, J.-C.; Lagniel, G.; Chedin, S.; Legros, V.; Mathon, M.-H.; Renault, J.-P.; Pin, S.; Boulard, Y.; Labarre, J., Structural Determinants for Protein adsorption/nonadsorption to Silica Surface. Plos One 2013, 8 (11), e81346.

2. Umpleby, R. J.; Baxter, S. C.; Chen, Y.; Shah, R. N.; Shimizu, K. D., Characterization of Molecularly Imprinted Polymers with the Langmuir-Freundlich Isotherm. Anal. Chem. 2001, 73 (19), 4584-4591.

3. Louit, G.; Hanedanian, M.; Taran, F.; Coffigny, H.; Renault, J. P.; Pin, S., Determination of hydroxyl rate constants by a high-throughput fluorimetric assay: towards a unified reactivity scale for antioxidants. Analyst 2009, 134 (2), 250-255.

4. Murai, N.; Taguchi, H.; Yoshida, M., Kinetic Analysis of Interactions between GroEL and reduced $\alpha$-Lactalbumin: effect of GroES and nucleotides. J. Biol. Chem. 1995, 270 (34), 19957-19963.

5. Nagaraj, N.; Wisniewski, J. R.; Geiger, T.; Cox, J.; Kircher, M.; Kelso, J.; Pääbo, S.; Mann, M., Deep proteome and transcriptome mapping of a human cancer cell line. Mol. Syst. Biol. 2011, 7, 548548.

6. Wien, F.; Wallace, B. A., Calcium Fluoride Micro Cells for Synchrotron Radiation Circular Dichroism Spectroscopy. Appl. Spectrosc. 2005, 59 (9), 1109-1113.

7. Lees, J. G.; Smith, B. R.; Wien, F.; Miles, A. J.; Wallace, B. A., CDtool-an integrated software package for circular dichroism spectroscopic data processing, analysis, and archiving. Anal. Biochem. 2004, 332 (2), 285-289. 